BMJ Nutrition,

Prevention \& Health

\title{
Could we be overlooking a potential choline crisis in the United Kingdom?
}

\author{
Emma Derbyshire (i)
}

Nutritional Insight, Surrey, UK

Correspondence to Dr Emma Derbyshire; emma@nutritional-insight.co.uk

Received 13 May 2019 Revised 17 June 2019 Accepted 21 June 2019 Published Online First 29 August 2019
Check for updates

(C) Author(s) (or their employer(s)) 2019. Re-use permitted under CC BY-NC. No commercial re-use. See rights and permissions. Published by BMJ.

To cite: Derbyshire E. bmjnph 2019;2:86-89.

\section{INTRODUCTION}

Choline can be likened to omega-3 fatty acids in that it is an 'essential' nutrient that cannot be produced by the body in amounts needed for human requirements. The United States (US) Institute of Medicine (IOM) ${ }^{1}$ and European Food Safety Authority (EFSA) ${ }^{2}$ recognise that choline plays an important role in the human body and have established dietary reference values. The American Medical Association $^{3}$ in 2017 published new advice stating that prenatal vitamin supplements should contain "evidenced-based" amounts of choline. Similarly the American Academy of Paediatrics ${ }^{45}$ (from 2018) called on paediatricians to move beyond simply recommending a "good diet" and to make sure that pregnant women and young children have access to food that provides adequate amounts of "brain-building" nutrients with choline being listed as one of these. Unfortunately, in the UK choline is not yet included in food composition databases, main nutrition surveys nor official recommendations. The present article discusses the current choline situation and explains why more needs to be done to include and monitor this essential nutrient in the UK.

\section{About choline}

Choline is an 'essential' nutrient for humans; and similar to omega-3 fatty acids, as the amount produced endogenously (in the liver) is not sufficient to meet human requirements ${ }^{6}$ it therefore needs to be obtained from dietary and supplement sources. Physiologically, choline is critical for a number of functions across the life cycle which include wide-ranging roles in human metabolism from neurotransmitter synthesis to cell structure and methylation, with choline deficiency being linked to liver disease, offspring cognitive function and potential neurological disorders. $^{78}$

Functionally choline in its oxidised form (the metabolite glycine betaine) contributes to S-adenosylmethionine synthesis - a chief methyl donor involved in DNA and histone methylation which play a central role in regulating gene expression and potentially modulating brain function. ${ }^{9}{ }^{10}$ Choline also influences liver function, with shortfalls linked to defective lipoprotein metabolism, abnormal phospholipid synthesis and oxidative damage. ${ }^{11}$

Low oestrogen status (oestrogen catalyses phosphatidylcholine conversion to choline via the phosphatidylethanolamine-Nmethyltransferase; PEMT enzyme) and genotype (eg, polymorphisms in the PEMT gene) can both alter choline dietary requirements. ${ }^{12}$ For the latter, a growing body of evidence exists suggesting that choline requirements may depend on the presence of several genotypes and that individuals with these could well have choline requirements higher than current recommended intakes. ${ }^{13} 14$

The risk of choline inadequacies, either due to low habitual intake or gene polymorphisms, is particularly concerning at key stages of the life cycle such as pregnancy and lactation. Choline is actively transported to the fetus in utero, with maternal supplies correlating with cognitive outcomes. ${ }^{15}$ This nutrient is particularly critical during fetal development as it modifies brain and spinal cord structure (via apoptosis and stem cell proliferation) influencing the risk of lifelong memory function and possible risk of neural tube defects. ${ }^{16}$

In pregnancy, choline supplementation at about twice the recommended amount (930 $\mathrm{mg}$ ) improves infant information processing speed. ${ }^{17}$ It has also been suggested that additional choline could improve affective, cognitive and neural functioning when taken by mothers carrying a fetus with Down syndrome. ${ }^{18}$ Among lactating mothers, both intake of choline and genetic polymorphisms influence choline concentrations in human breast milk, subsequently impacting on levels transferred to the infant. ${ }^{19}$ Human neonates are also born with choline blood levels around 
Table 1 United States Institute of Medicine and European Food Safety Authority Adequate Intake recommendations for choline

\begin{tabular}{|c|c|c|c|c|c|c|}
\hline \multirow[b]{2}{*}{ Life stage } & \multicolumn{4}{|c|}{ US IOM (1998) AI (mg/day) ${ }^{1}$} & \multicolumn{2}{|c|}{ EFSA (2016) Al (mg/day) ${ }^{2}$} \\
\hline & Age (years) & Males & Females & UL (mg/day) & Age (years) & Al \\
\hline Adult & $\geq 19$ & 550 & 425 & 3500 & $\geq 18$ years & 400 \\
\hline Lactation & - & - & 550 & 3500 & & 520 \\
\hline
\end{tabular}

Al, Adequate Intake; EFSA, European Food Safety Authority; IOM, Institute of Medicine; UL, Tolerable Upper Intake Level; US, United States.

three times higher than maternal levels, indicating high demands during this life stage. ${ }^{20}$

\section{Authoritative choline recommendations}

Nearly two decades ago in 1998 it was the US IOM that first established choline intake recommendations. ${ }^{1}$ As shown in table 1, the Adequate Intake (AI) for choline was set at $550 \mathrm{mg} /$ day for males and $425 \mathrm{mg} /$ day for non-pregnant females aged 19 years and over. This was based on amounts that prevented hepatic dysfunction in human studies, defined as elevated aminotransferase in serum. For pregnancy and lactation, increments were added for fetal and placental accumulation and choline output in mature milk, increasing requirements to 450 and $550 \mathrm{mg} /$ day, respectively.

More recently in 2016 the $\mathrm{EFSA}^{2}$ re-evaluated the evidence and also compiled dietary requirements for choline. Once again AIs were compiled, with these being set at $400 \mathrm{mg}$ /day for all adults, based on observed average choline intakes in healthy European populations and after considering the amount of choline needed to replete around $70 \%$ of depleted subjects in a depletion/ repletion study. Again, upward adjustments were made for pregnant and breastfeeding women to account for the mean gestational rise in body weight and lactation based on the amount of choline in human milk during the first 6 months of exclusive breastfeeding. Thus, intakes of 480 and $520 \mathrm{mg}$ /day are advised for pregnancy and lactation, respectively.

In 2011 the $\mathrm{EFSA}^{21}$ authorised a number of cholinerelated health claims. It was concluded that a cause and effect relationship had been established between the following: (1) "choline is needed for lipids metabolism", (2) "maintaining healthy liver functioning" and (3) "reduction in homocysteine levels". At that time evidence in relation to choline consumption and the maintenance of normal neurological function, cognitive function or brain and neurological development was not thought to be sufficient.

\section{Food sources and changing trends}

It is well appreciated that animal foods contain more choline per unit weight than plant sources. ${ }^{22}$ In general, beef, eggs, fish, chicken, nuts, milk and certain plant foods such as cruciferous broccoli provide some dietary choline. ${ }^{23}$ Other examples of food sources providing choline and the amount per $100 \mathrm{~g}$ are shown in figure 1.
Relevantly, European research ${ }^{24}$ has shown that habitual choline intakes are, on average, below the AI established in 1998 by the IOM, and that meat, milk, eggs, grains and their derived products were the predominant sources of dietary choline.

In one publication ${ }^{25}$ using US National Health and Nutrition Examination Survey data (NHANES; 2009-2014 datasets) achievement of the AI for choline was extremely difficult without the consumption of eggs or taking a dietary supplement. For example egg consumers had almost twice the usual choline intake compared with nonconsumers. The survey also showed that protein, meat and seafood consumption were associated with increased choline intakes compared with non-consumers. In the UK such an analysis has not been conducted, although red meat and processed meat intakes among those aged 19-64 years have declined by 19 g over the last 9 years. ${ }^{26}$

Other work ${ }^{27}$ based on the NHANES datasets showed that only around $11 \%$ of American adults achieve the IOM AI for choline. In Europe it has also been found that average choline intakes are below AI thresholds set by the IOM. ${ }^{23}$ In Alberta, Canada one study ${ }^{28}$ showed that only $23 \%$ of pregnant women and $10 \%$ of lactating mothers $(\mathrm{n}=600)$ met the choline AI recommendation and that the main dietary sources of choline were eggs, dairy products and meat. Women consuming at least one egg daily were eight times more likely to meet choline intake recommendations compared with pregnant non-consumers.

This is interesting yet equally concerning given that current trends appear to be towards meat reduction and plant-based diets. ${ }^{29}{ }^{30}$ The recent 2019 EAT-Lancet ${ }^{31}$

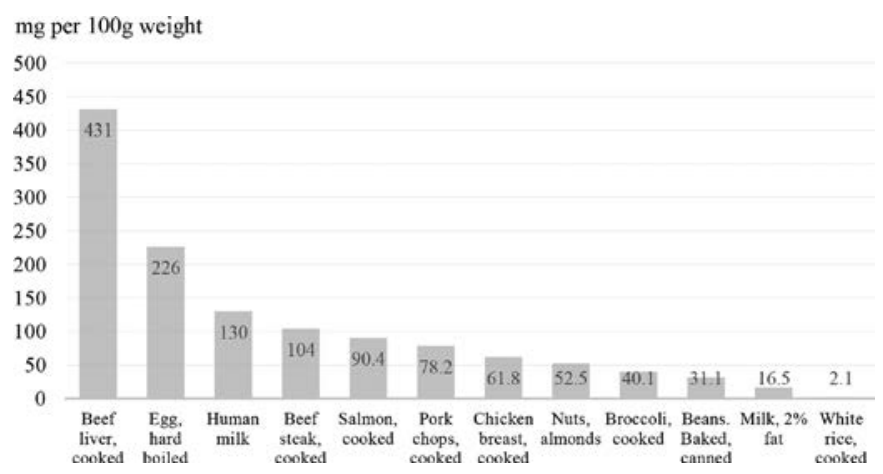

Figure 1 Different food sources providing choline. Values are for total choline, the sum of individual choline forms. Source: data extracted from Wiedeman et al (2018). ${ }^{23}$ 
publication has compiled a healthy reference diet, based on an adult dietary intake of $2500 \mathrm{kcal} /$ day. While this should be praised in that it is the first report to compile a healthy food plan based on promoting environmental sustainability, restricted intakes of whole milk, eggs and animal protein could impact on choline intakes and status. For example, just $7 \mathrm{~g}$ beef and lamb, $13 \mathrm{~g}$ egg and $250 \mathrm{~g}$ whole milk or derivative equivalents such as cheese are advised, although ranges are also provided. Given the acceleration of these dietary trends, their impact on choline intakes is a crucial area worthy of consideration and further study.

\section{The need for more research in the UK}

Given the important physiological roles of choline and authorisation of certain health claims it is questionable why choline has been overlooked for so long in the UK. Choline is presently excluded from UK food composition databases, major dietary surveys and dietary guidelines. In Australia, for example, the AUSNUT 2011-13 database ${ }^{32}$ has now been expanded to include Australian choline values. Composite foods, and 'not further-specified foods', were developed using the Food Standards Australia New Zealand (FSANZ) recipe files, and when applied it was discovered that less than $10 \%$ of the population were found to achieve the AI for choline (eggs again ranked top as a contributor).

Similar approaches could be adopted to the UK McCance and Widdowson database ${ }^{33}$ as a starting point for quantifying habitual choline intakes in the UK. This database was recently updated in 2019 but choline was not included. These data could then be embedded, used to quantify habitual intakes in the UK, and be reported alongside other B vitamins such as folate in the National Diet and Nutrition Survey. Likewise, now the time may also be right for a Scientific Advisory Committee on Nutrition call, relating to the inclusion of choline as part of UK Dietary Guidelines.

\section{Summary and perspective}

The mounting evidence of choline's importance makes it essential that it does not continue to be overlooked in the UK. This is now more important than ever given that accelerated food trends towards plant-based diets/ veganism could have further ramifications on choline intake/status. Government bodies and organisations should look to extended datasets to include this essential nutrient. So far, looking at the evidence-base we know that:

- Choline is a critical nutrient needed for neurocognition, lipid metabolism, liver function and homocysteine regulation.

- The majority of Europeans, American, Canadian and Australian populations are not meeting choline AI recommendations.

- Eggs, milk and meat appear to be major dietary providers and further movements away from the consumption of these could have unintended consequences for choline intake/status.

- Ongoing nutrition research must study 'long-term' intakes of choline e.g. using food frequency questionnaires rather than 24-hour recalls, which will give a more reliable picture of choline intakes.

- More needs to be done to educate health care professionals and consumers about the importance of a choline-rich diet and how to achieve this.

- If choline is not obtained in the levels needed from dietary sources per se then supplementation strategies will be required, especially in relation to key stages of the life-cycle such as pregnancy, when choline intakes are critical to infant development. ${ }^{34}$

Correction notice This article has been corrected since it was published online. The 'Competing interests' section has been updated.

Contributors Contributors: ED contributed to conceptualising and writing the manuscript. Declarations: ED has previously sat on Choline Advisory Panels but did not receive funding for the writing of this article nor its open access fees.

Funding The authors have not declared a specific grant for this research from any funding agency in the public, commercial or not-for-profit sectors.

Disclaimer ED has previously sat on Choline Advisory Panels but did not receive funding for the writing of this article nor its open access fees.

Competing interests ED has written this article independently and did not receive funding for writing it. It was written solely to raise choline awareness. She has, however, consulted for and advised: The Meat Advisory Panel, Marlow Foods (Quorn), the Health Supplement Information Service and the British Egg Information Service, amongst others.

Provenance and peer review Not commissioned; externally peer reviewed.

Data availability statement There are no data in this work. No data are available.

Open access This is an open access article distributed in accordance with the Creative Commons Attribution Non Commercial (CC BY-NC 4.0) license, which permits others to distribute, remix, adapt, build upon this work non-commercially, and license their derivative works on different terms, provided the original work is properly cited, appropriate credit is given, any changes made indicated, and the use is non-commercial. See: http://creativecommons.org/licenses/by-nc/4.0/.

ORCID iD

Emma Derbyshire http://orcid.org/0000-0002-9201-4666

\section{REFERENCES}

1. Institute of Medicine. Food and Nutrition Board (1998) Dietary Reference Intakes: Thiamin, Riboflavin, Niacin, Vitamin B6, Folate, Vitamin B12, Pantothenic Acid, Biotin, and Choline. In: . Washington, DC: National Academies Press, 1998.

2. European Food Safety Authority. Dietary reference values for choline. EFSA Panel on Dietetic Products, Nutrition and Allergies (NDA) EFSA Journal 2016;14.

3. American Medical Association (2017) AMA backs global health experts in calling infertility a disease. Available: https://www.amaassn.org/delivering-care/public-health/ama-backs-global-healthexperts-calling-infertility-disease [Accessed 29th April 2019].

4. American Academy of Pediatrics (2018) food for thought: AAP aims to ensure kids get key nutrients for brain development. Available: https://www.aap.org/en-us/about-the-aap/aap-press-room/Pages/ Food-for-Thought-AAP-Aims-to-Ensure-Kids-Get-Key-Nutrients-forBrain-Development.aspx [Accessed 29th April 2019].

5. Schwarzenberg SJ, Georgieff MK, Committee on Nutrition. Advocacy for improving nutrition in the first 1000 days to support childhood development and adult health. Pediatrics 2018;141:e20173716-10.

6. Zeisel SH. Choline. In: Caballero B, Cousins RJ, Tucker KL, et al, eds. Modern Nutrition in Health and Disease, 11th ednBaltimore: MD, USA, 2014: 416-26.

7. Zeisel SH, da Costa K-A. Choline: an essential nutrient for public health. Nutr Rev 2009;67:615-23. Volume. 
8. Jiang X, West AA, Caudill MA, et al. Maternal choline supplementation: a nutritional approach for improving offspring health? Trends Endocrinol Metab 2014;25:263-73.

9. Bekdash RA. Choline and the brain: an epigenetic perspective. Adv Neurobiol 2016;12:381-99.

10. Hollenbeck CB. An introduction to the nutrition and metabolism of choline. Cent Nerv Syst Agents Med Chem 2012;12:100-13.

11. Corbin KD, Zeisel SH. Choline metabolism provides novel insights into nonalcoholic fatty liver disease and its progression. Curr Opin Gastroenterol 2012;28:159-65.

12. Fischer LM, da Costa K-A, Kwock L, et al. Dietary choline requirements of women: effects of estrogen and genetic variation. Am J Clin Nutr 2010;92:1113-9.

13. Ganz A, Klatt K, Caudill M, et al. Common genetic variants alter metabolism and influence dietary choline requirements. Nutrients 2017;9:837

14. Ganz A, Cohen V, Swersky C, et al. Genetic variation in cholinemetabolizing enzymes alters choline metabolism in young women consuming choline intakes meeting current recommendations. Int J Mol Sci 2017;18:252.

15. Bernhard W, Raith M, Kunze R, et al. Choline concentrations are lower in postnatal plasma of preterm infants than in cord plasma. Eur J Nutr 2015;54:733-41.

16. Zeisel $\mathrm{SH}$. Choline: critical role during fetal development and dietary requirements in adults. Annu Rev Nutr 2006;26:229-50.

17. Caudill MA, Strupp BJ, Muscalu L, et al. Maternal choline supplementation during the third trimester of pregnancy improves infant information processing speed: a randomized, double-blind, controlled feeding study. FASEB J 2018;32:2172-80.

18. J. Strupp B, E. Powers B, Velazquez R, et al. Maternal choline supplementation: a potential prenatal treatment for Down syndrome and Alzheimer's disease. Curr Alzheimer Res 2015;13:97-106.

19. Fischer LM, da Costa KA, Galanko J, et al. Choline intake and genetic polymorphisms influence choline metabolite concentrations in human breast milk and plasma. Am J Clin Nutr 2010;92:336-46.

20. Caudill MA. Pre- and postnatal health: evidence of increased choline needs. J Am Diet Assoc 2010;110:1198-206.

21. European Food Safety Authority. Scientific opinion on the substantiation of health claims related to choline and contribution to normal lipid metabolism (ID 3186), maintenance of normal liver function (ID 1501), contribution to normal homocysteine metabolism (ID 3090), maintenance of normal neurological function (ID 1502), contribution to normal cognitive function (ID 1502), and brain and neurological development (ID 1503) pursuant to Article 13(1) of Regulation (EC) No 1924/2006. EFSA Journal 2011;9.

22. Zeisel SH, Klatt KC, Caudill MA. Choline. Adv Nutr 2018:9:58-60.

23. Wiedeman A, Barr S, Green T, et al. Dietary choline intake: current state of knowledge across the life cycle. Nutrients 2018;10:1513.

24. Vennemann FBC, loannidou S, Valsta LM, et al. Dietary intake and food sources of choline in European populations. Br J Nutr 2015;114:2046-55.

25. Wallace T, Fulgoni V. Usual choline intakes are associated with egg and protein food consumption in the United States. Nutrients 2017;9:839.

26. Public Health England. Statistical summary: national diet and nutrition survey: years 1 to 9 of the rolling programme (2008/09 2016/17): time trend and income analyses, 2019. Available: https:// assets.publishing.service.gov.uk/government/uploads/system/ uploads/attachment data/file/772430/NDNS Y1-9 statistical summary.pdf [Accessed 4th June 2019].

27. Wallace TC, Fulgoni VL. Assessment of total choline intakes in the United States. J Am Coll Nutr 2016;35:108-12. 3rd.

28. Lewis ED, Subhan FB, Bell RC, et al. Estimation of choline intake from $24 \mathrm{H}$ dietary intake recalls and contribution of egg and milk consumption to intake among pregnant and lactating women in Alberta. Br J Nutr 2014;112:112-21.

29. Michelozzi P, Lapucci E, Farchi S, et al. [Meat consumption reduction policies: benefits for climate change mitigation and health]. Recenti Prog Med 2015;106:354-7.

30. Szabó Z, Erdélyi A, Gubicskóné Kisbenedek A, et al. [Plant-based diets: a review]. Orv Hetil 2016;157:1859-65.

31. Willett W, Rockström J, Loken B, et al. Food in the Anthropocene: the EAT-Lancet Commission on healthy diets from sustainable food systems. The Lancet 2019;393:447-92.

32. Neale E, Guan V, Neale E. Development of a choline database to estimate Australian population intakes. Nutrients 2019:11:E913.

33. Public Health England. Composition of Foods Integrated Dataset (CoFID). McCance and Widdowson's 'Composition of Foods Integrated Dataset' on the nutrient content of the UK food supply, 2019. Available: https://www.gov.uk/government/publications/ composition-of-foods-integrated-dataset-cofid [Accessed 4th June 2019].

34. Zeisel SH. The supply of choline is important for fetal progenitor cells. Semin Cell Dev Biol 2011;22:624-8. 